\title{
The Mindful Action Plan: Using the MAP to Apply Acceptance and Commitment Therapy to Productivity and Self-Compassion for Behavior Analysts
}

\author{
Daniel J. Moran ${ }^{1} \cdot$ Siri Ming ${ }^{2}$ (D) \\ Published online: 28 July 2020 \\ (C) Association for Behavior Analysis International 2020
}

\begin{abstract}
The COVID-19 public health emergency created an aversive environment for people all around the world. Acceptance and commitment therapy (ACT), born of behavior analysis, can help address some of these problems by encouraging behavioral change and increasing psychological flexibility. The mindful action plan (MAP) is designed to create a simple approach to utilizing the ACT principles. The MAP utilizes the traditional ACT hexagon model and provides a checklist for learning and following through on the 6 components that, when combined, lead to psychological flexibility. The MAP guides people to act in the direction of their values and to be influenced by their verbal behavior while saying, "I am here now, accepting my feelings and noticing my thoughts while doing what I care about." Specific instructions and exercises are provided so the MAP can be used by behavior analysts to assist their actions during stressful and anxiety-provoking times.
\end{abstract}

Keywords Acceptance and commitment therapy · Committed action · COVID-19 · Mindful action plan · Mindfulness

"I am here now, accepting my feelings and noticing my thoughts while doing what I care about." The verbal behavior in this phrase sets the occasion for values-based responses in the presence of aversive stimuli. When things are difficult - as they are now for all of us faced with the social, economic, and personal upheaval caused by the COVID-19 public health emergency (hereafter referred to as the pandemic) — orienting toward what matters most to us helps us find our footing and move forward. Acceptance and commitment therapy (ACT; Hayes, Strosahl, \& Wilson, 2012) can assist behavior analysts

\section{Editor's Note}

This manuscript is being published on a highly expedited basis, as part of a series of emergency publications designed to help practitioners of applied behavior analysis take immediate action to adjust to and mitigate the COVID-19 crisis. This article was submitted on April 18, 2020, and received final acceptance on April 20, 2020. The journal would like to especially thank Dr. Alyssa Wilson for her expeditious review of the manuscript. The views and strategies suggested by the articles in this series do not represent the positions of the Association for Behavior Analysis International or Springer Nature.

Siri Ming

siri@siriming.com

1 Long Island University Post, Greenvale, NY, USA

2 Private Practice, Baltimore, MD, USA during this pandemic by providing a framework for addressing the kinds of aversive private events that often evoke escape or avoidance behavior. Such experiential avoidance may provide relief from uncomfortable private events in the short term, but it can also create a barrier to contacting larger and more delayed reinforcement in the long term. ACT focuses on helping individuals live meaningful, values-directed lives even under the most difficult of circumstances. Now more than ever, this focus is needed.

ACT has been applied to many clinical concerns, such as anxiety (Kelson, Rollin, Ridout, \& Campbell, 2019), and substance abuse (Ii et al., 2019), and has a substantial evidence base across diagnostic categories (A-Tjak et al., 2015). ACT also contributes more generally to well-being (Howell \& Passmore, 2019). ACT training (ACTraining, e.g., Little, Tarbox, \& Alzaabi, 2020; Moran, 2015) has emerged as a framework for teaching skills to help individuals live more meaningful lives, whether that be in one's personal or professional spheres. For example, applications of ACTraining in the workplace have demonstrated a significant influence on improving productivity, reducing errors, accelerating leadership skills, and acquiring new skills from recent training (Moran, 2011). ACTraining has also been shown to result in improved client engagement by direct care workers in applied behavior analysis (ABA; Castro, Rehfeldt, \& Root, 2016) and 
has improved the use of behavioral skills training by staff trainers (Little et al., 2020).

Both ACT and ACTraining have a primary aim to increase psychological flexibility, which is the ability to

contact the present moment while also being aware of thoughts and emotions - without trying to change those private experiences or be adversely controlled by them - and depending upon the situation, persisting in or changing behavior in the pursuit of values and goals. (Moran, 2015, p. 26)

Doorley et al. (2020) define psychological flexibility as "the ability to pursue valued life aims despite the presence of pain" (p. 2). Key to both these definitions is the focus on one behaving in line with his or her pursuit of larger, long-term reinforcers, despite the presence of aversive private events.

When one is faced with stress, crisis, and trauma - whether personal or global-aversive private events will occur. Uncomfortable conditioned and unconditioned responses of fear, sadness, and worry (i.e., feelings) are elicited, along with private verbal behavior (i.e., thoughts) evoked by both environmental stimuli and our own emotional responses. That verbal behavior in turn transforms the stimulus functions of environmental events, which then elicit and evoke even more aversive feelings and thoughts. Oftentimes, our culturally reinforced response is to try to avoid all of it. It is an unwinnable cycle.

A complete explication of complex human behavior and the impact of trauma is beyond the scope of this article (c.f. Walser \& Westrup, 2007). It is self-evident that behavior analysts often work under stressful conditions in typical circumstances, and the pandemic has highlighted the need for us to have tools to handle the significant increase in stress. Whether we are discussing the typical stress of working with individuals with severe challenging behaviors, the new stress of continuing to provide essential services where social distancing is unfeasible, the anxiety of isolation, the frustrations of having to deal with telehealth technology, or the worries about receiving the next paycheck, behavior analysts are certainly faced with aversive situations. Under the current conditions, we all need help improving skills for psychological flexibility and for acting effectively toward valued living. ACT provides such a framework for behavior change.

The traditional method of applying ACT is using the ACT hexagon model (see Fig. 1); the six components of the hexagon include (a) self-as-context, (b) contact with the present moment, (c) acceptance, (d) defusion, (e) committed action, and (f) values. Each of these components is skills based and contributes to psychological flexibility, whether taught within a therapeutic context or in ACTraining (e.g., in an organizational behavior management context). The mindful action plan (MAP), rooted in ACT, creates a checklist with these six component skills to help build psychological flexibility: (a) I am (b) here now, (c) accepting the way I feel and (d) noticing my thoughts while (e) doing (f) what I care about.

Checklists have been shown to assist productivity (Gawande, 2011) and can contribute to organizational behavior management initiatives (Bacon, Fulton, \& Malott, 1982). As a checklist, the MAP (Fig. 2; bit.ly/MindfulActionPlan) can help individuals stay committed to the six processes of utilizing ACT for self-directed activities. You are encouraged to print out a copy of the MAP and follow along with the instructions throughout this article to get the most out of your reading. Doing this exercise with pen and paper can make this process more impactful (see Mueller \& Oppenheimer, 2014). The ACT statement is printed at the top of the MAP, and Table 1 demonstrates the point-to-point relationship that the six components of the MAP have with the six components of the ACT hexagon model. Basically, the MAP is a simplified version of ACT, with the integration of reminders related to performance management principles, which are fundamental to traditional behavior analysis. The MAP can be used for many different human endeavors, including group psychotherapy (Westrup \& Wright, 2017) and safety endeavors (Moran, 2013). This article will focus on how the MAP can assist ABA professionals in learning the skills to harmonize productivity and self-care during the pandemic. With the MAP and ACT, ABA can help applied behavior analysts.

\section{ACT and the Components of the MAP}

\section{Self-as-Context: I Am}

Self-as-context skills aim to build psychological flexibility by shaping an individuals' perspective taking on who they are and how they describe themselves. ACT teaches people to come in contact with the experience that they are a verbally skilled individual, and therefore, has a consistent perspective from which they experience all changing events, and that such a perspective remains unchanged by these events. The perspective of self-as-context (also known as "the observing you" or "pure awareness") helps individuals let go of any self-descriptions that are unhelpful to values-based action. For example, during the pandemic, a Board Certified Behavior Analyst (BCBA) who works $60 \mathrm{hr}$ a week at the clinic that she founded is told that she needs to close her facility for a month due to state guidelines to shelter in place. She immediately starts having private verbalizations describing her current sense of herself given the anxiety-provoking situation: "I am a hard worker and must continue to be massively productive during this shutdown! I have to write articles and publish data while the clinic is shuttered!" Such statements, which reflect her previous ideas about her professional role and what it means to be a good behavior analyst, may lead 
Fig. 1. The ACT hexagon

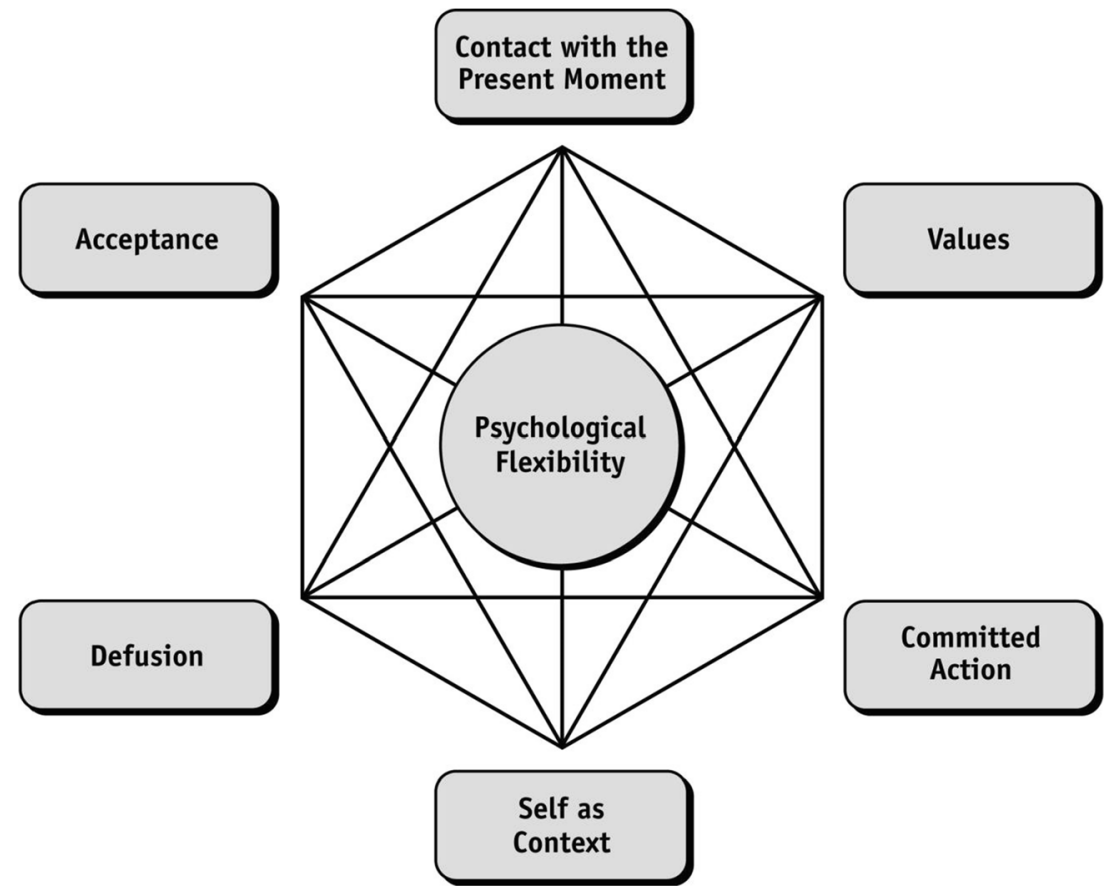

her to develop an unhealthy work process. Given the global influence of the health crisis, the BCBA may be trying to measure up to an ideal work rate given the new "time off" from work, but because of the ubiquitous uncertainty about the state of the world, and palpable environmental obstacles to productivity, she may begin judging that her productivity is not enough. ACTraining invites individuals to simply observe their unhelpful self-talk and take a wider point of view on who they are. ACT helps you learn to identify that you are not your roles, titles, emotions, sensations, thoughts, or urges, but that these are simply experiences you have. This perspective allows the person to behave more flexibly in the presence of these stimulus events that could increase stress levels. Such psychological flexibility allows individuals to engage in values-based actions for self-compassion and sets the occasion for people to actually not be driven to work themselves to exhaustion because they are no longer attached to labels such as "a hard worker" or "massively productive."

The "I am" component of the MAP comports with the perspective of self-as-context and gives this suggestion: Notice if you are being influenced by any unhelpful self-descriptions. Let go of any problematic thoughts that you are believing about yourself.

Letting go is certainly easier said than done, but it is a skill that can be learned, practiced, and continually improved. Try this:

Take a few moments to sit quietly and focus on your breathing. Bring up a memory of something you were doing 1 year ago and try to remember it as vividly as you can. Imagine you are watching a movie from your perspective of what was happening back then. See the sights and hear the sounds. Make it very clear to yourself that you were there, then, experiencing that. Continue viewing that memory for a few more moments before reading more of this exercise. After watching these thoughts, take another slow inhale and make it very clear to yourself that you are here, now, experiencing this. Immerse yourself in this experiential fact: Something about you has been you throughout your life. The experience of "you" that is here now was there then in the memory from last year. There is something about all verbally skilled people that sets up a context for us to perceive events from a "self." This experience has been available to you throughout your life after you started acquiring verbal behavior skills and getting social reinforcement for talking about your responses to the environment. You were, and continue to be, reinforced for making statements about your environment-behavior interactions by saying "I am . . ." You may make statements describing your roles, body, emotions, and sensations, such as "I am a behavior analyst," "I am tall," "I am happy," and "I am nauseous." Those statements vary from each other, but they all include perspective taking and the phrase "I am." Can you - in this exercise right now-come as fully into contact with that "I am" experience? At the very core, you are not your roles, body, emotions, or sensations. You are the context within which you have those experiences. The "I am" core to 


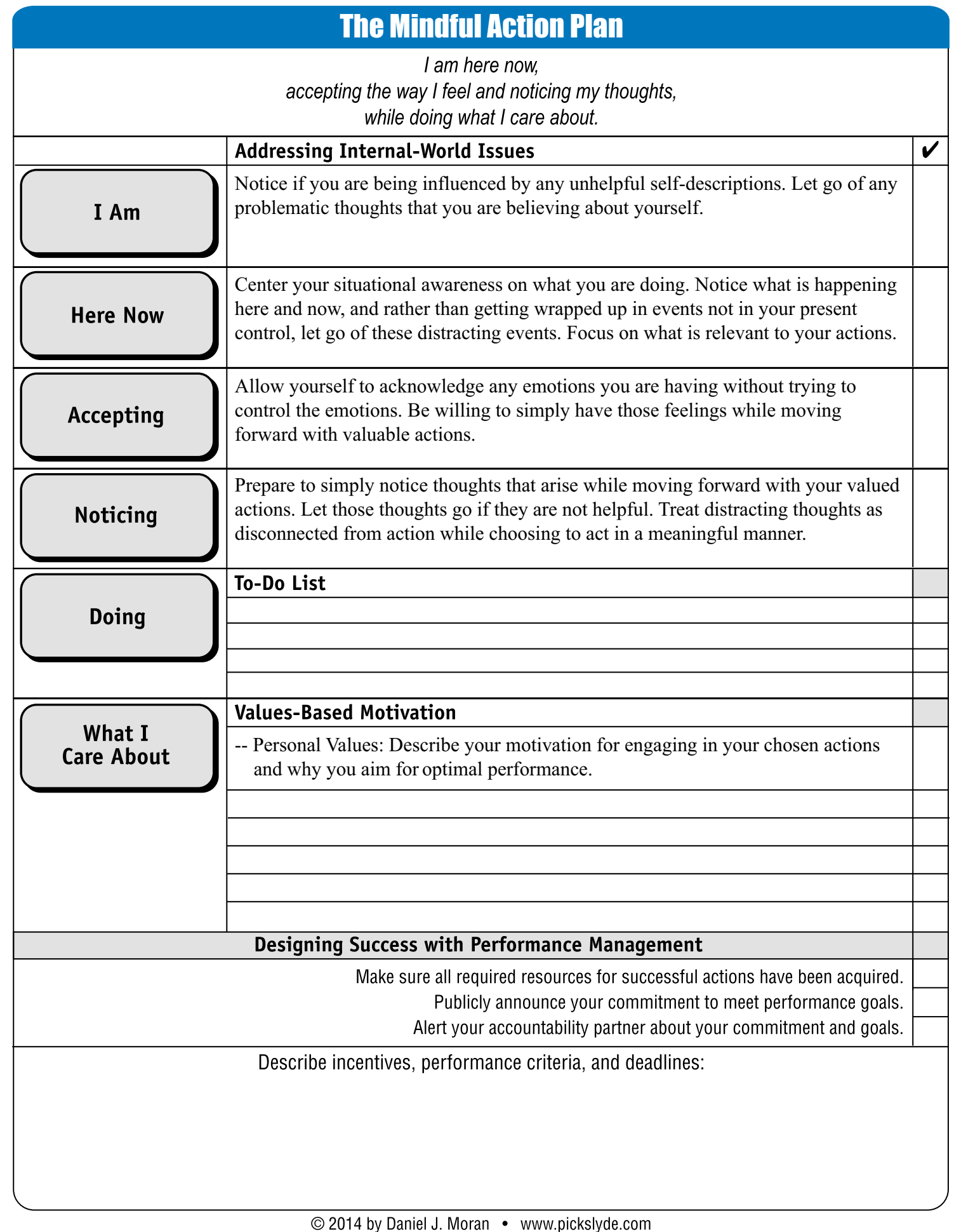

Fig. 2. The mindful action plan

your verbal behavior remains solid and is unbroken and unchanged throughout your life. Take a moment in this exercise to fully ground yourself in the "I am" experience. And now, turn to letting go of the other verbal selfdescriptions. The core "you" is not "a behavior analyst" or "tall." Those are verbal descriptions of a role that you engage in and the relative size of your body. Those verbalizations are not you. Can you also let go of other verbalizations from the "I am" perspective? Can you simply notice that you have a history of tacting "happy" when a temporary emotion is present and that such a description is not of you but of a temporary feeling? 
Table 1. Matching the ACT and MAP Components

\begin{tabular}{lll}
\hline & The ACT Components & The MAP Components \\
\hline 1 & Self-as-context & I am . . \\
2 & Contact with the present moment & Here now \\
3 & Acceptance & Accepting \\
4 & Defusion & Noticing \\
5 & Committed action & Doing \\
6 & Values & What I care about \\
\hline
\end{tabular}

The same can go for the sensation of being "nauseous." Sensations, emotions, and other private events come and go, and therefore you can build a skill of relating differently to the verbalization about these experiences and let go of those events being you. When faced with stress and psychological inflexibility, aim to come back to that steadfast context of the "I am" experience, while letting go of other descriptions related to the self and other private events.

\section{Present Moment Mindfulness: Here Now}

Contact with the present moment relates to the core concepts of mindfulness and meditation training. "Now" is the only time people can engage in any response; however, according to Killingsworth and Gilbert (2010), for $47 \%$ of the day, people are attending to something other than their current actions. The human ability to engage in verbal behavior gives people the skills for remembering past events, comparing the current situation to an ideal situation, and planning future actions. This repertoire pays handsome dividends but also can prevent individuals from paying attention to what is going on in the current moment. This is the downside to verbal behavior. For example, during the pandemic, a Board Certified Assistant Behavior Analyst who has been deemed an essential worker at the residential facility where she is employed worries throughout the day if she is exposing her clients to the virus or if she is going to expose her family to the virus. She worries that she is not doing a good enough job with her clients and that she is not doing enough to help her child with his virtual school lessons. She ruminates, "What if I get sick and can't work? How will I protect my family, and what will we do for income?" At home, when trying to help her son, she finds herself worrying about whether or not she disinfected properly when she left the residential facility and snaps at him when he asks about his math problems.

These private verbal events influence her to focus on things not in her present control, and in turn, reduce her focus on executing behavior that is in her control: following safety protocols, doing a good job as a behavior analyst supervising staff and managing behavior plans, and being present with her son. Her distracted thoughts lead her to occasionally stare off into space with worry, and her managers begin noticing that she is not interacting as much with the clients who need her assistance. Her psychological inflexibility with respect to her thoughts and actions is actually exacerbating her problems. The more she worries about doing a good enough job at work or at home, the worse her performance actually is. Engaging in mindfulness exercises from an ACTraining perspective can assist her to attend to the present moment - which is the only time she can take effective action - and help her engage in effective committed actions related to her values.

The "here now" component to the MAP comports with the contact with the present moment, and gives this directive: Center your situational awareness on what you are doing. Notice what is happening here and now, and rather than getting wrapped up in events that are not in your present control, let go of these distracting events. Focus on what is relevant to your actions.

It may seem very difficult right now to focus on anything at all, but again, this is a skill to be learned. Try this now:

Take a moment to embrace what is happening in this moment. Contact your five senses. Look at five things you can see, and realize that you are seeing them now. Observe what you can smell and taste, and realize that you are engaging in those actions right now. Touch something, even if that just means sensing the clothes on your skin or your body in the chair, and simply observe your sense of touch right now. Listen. Hear three things if you can. Attempt to perceive a sound close by, one from a middle distance, and one from far away, and realize that you are doing this in the present moment. Be in this present moment. Reorienting your attention to being here now is a skill, and it is a worthy capability to pursue because, whereas your verbal behavior may influence you to focus on past and future events, your behavior only happens in the present moment. If you can link your values to what you do with your response, then it can be highly reinforcing to continue to use the skills that keep you in the present moment because the "here now" is the only time and place behavior happens.

\section{Acceptance: Accepting}

Acceptance skills contribute to psychological flexibility by influencing individuals to behave successfully in the presence of private events (e.g., sensations and emotions) that are commonly perceived as stressful (Hayes, Wilson, Gifford, Follette, \& Strosahl, 1996). During ACTraining, individuals acquire the skills to view and relate with private psychological 
experiences as natural reactions to environmental stimuli and learn that such feelings, urges, and sensations do not need to be escaped or avoided. The ACT perspective advocates that willingly coming in contact with such private events and experiences is healthier and allows the individual to behave more effectively. Engaging in responses to escape or avoid private experiences may actually contribute to ineffective and potentially clinically relevant behavior (Boeschen, Koss, Figuerdo, \& Coan, 2001; Roemer, Litz, Orsillo, \& Wagner, 2001). For instance, during the pandemic, when a registered behavior technician is told that the clinic where he is employed has to close indefinitely, this loss of connecting with his students and coworkers, and the potential loss of income, can elicit fear responses. If he engages in fear avoidance by drinking copious amounts of alcohol, he may be cutting himself off from opportunities for engaging in other values-based activities, such as engaging in his hobbies or interacting more with his family, because he is intoxicated more frequently or dealing with feeling hungover. ACTraining aims to develop a willingness to experience a range of psychological events - such as stress - so avoidance responses do not divert the person's performance from valuesbased ends.

The "accepting" component of the MAP comports with acceptance in the ACT model and gives the following recommendation: Allow yourself to acknowledge the emotions you are feeling without trying to control the emotions. Be willing to simply have those feelings while moving forward with valuable actions.

We will keep saying it - this too is a skill that can be learned. Even if accepting your difficult emotions right now seems impossible, you can learn to do so. Acceptance is often taught with metaphor in ACT (Törneke, 2017), and the following exercise can be applicable for any uncomfortable emotion you are experiencing, such as rage, grief, or exhaustion. Before beginning, make a point of tacting your most recent painful feeling and contact the experience of having an emotion you find aversive. Attempt to apply this metaphorical exercise to this feeling:

Focus on how you are feeling right now, especially the challenging emotions and sensations that are coming up at this time. Perhaps you feel anxious, sad, angry, or dull, and you might be interacting with these private events as if they were aversive, or with personal experiences you are working to avoid. Can you perceive these emotions and sensations as things that are uncomfortably attached to you and inescapable? Imagine the experience is truly a ball and chain. Don't just think of it figuratively, but rather imagine - as literally as you can - that you are burdened with a 17th-century shackle that was used on prisoners. Come in contact with the weight, the discomfort, and the difficulty in dealing with this thing that you do not want and did not ask for. As you try to live your day moving around your environment, this ball and chain prevents you from traveling in your valued directions. You try to escape from the manacles, but the harder you pull and the faster you try to run away, the more exhausting and painful they become. What can be done when you are shackled to this burden? Consider doing something unconventional and counterintuitive: Accept the burden. What if you willingly allowed yourself to fully come in contact with that thing you are trying to escape? What if you looked at the ball and chain directly, and then picked it up with both hands, and held it close to you? What if you accepted its presence, fully and without defense, to the point of embracing it? Can you then cradle the ball and chain tightly under your arm, the way a mother holds a newborn? What would then happen to your movement around your environment as you travel in your valued directions? Accepting that which you find aversive, embracing it, and holding it closely can assist you in engaging in vital and meaningful behaviors.

\section{Defusion: Noticing}

Defusion skills assist individuals to observe their own private verbal behavior (i.e., thinking) without being governed by it. In contrast, fusion is when private verbal behavior rigidly directs an individual's actions (Blackledge, 2007). It is impossible to "control" one's thoughts (as anyone who has tried not to think of a pink elephant can testify to), especially in stressful environments, and such environments are likely to evoke unproductive or unhelpful thoughts. For instance, consider a director of a preschool who thinks to herself, "This world is a mess, and nothing matters anymore!" If she is fused to her thoughts, those stimulus events might occasion her to engage in actions that have a deleterious impact on her career goals. She might resist writing up case notes that were due last week, prevent herself from establishing her clinic's first teleconferencing meeting, and avoid taking advantage of free online continuing education opportunities. ACTraining teaches defusion skills to help individuals mindfully witness unproductive thoughts, and encourages individuals to engage in purposeful action in the occurrence of these verbal hindrances.

The "noticing" component of the MAP comports with defusion in the ACT model and gives this recommendation: Prepare to simply notice thoughts that arise while moving forward with your valued actions. Let those thoughts go if they are not helpful. Treat distracting thoughts as disconnected from action while choosing to act in a meaningful manner.

The mindfulness exercise we introduced earlier is a good place to begin with practicing this skill. Let us extend that. 
Find an environment where you can take a few moments to engage in a simple and brief mindfulness exercise. Begin by repeating the aforementioned tasks for contacting the present moment. Become aware of your five senses. Take this opportunity to taste, see, hear, smell, and feel something.

Now become aware of private verbal behavior that accompanies these behaviors. While engaged in sensing, do you also have thoughts about your behaviors and what you are sensing? Throughout our lives as verbally able adults, the private events of thoughts are going to happen with a great deal of regularity. Human beings fluently make judgments, descriptions, or evaluations about their environment and their own responses. These private verbal events often govern overt behavior, but they do not have to cause behaviors to happen. Behavior analysis adamantly denies the causality of thinking on overt actions, and mindfulness traditions agree.

Can you simply notice that you are making judgments, descriptions, and evaluations? When you have a thought, rule, or provocative idea, you are invited to simply observe these events that are not in your control (and that are not in control of you). Imagine that your thoughts were sounds from a disc jockey on the radio and that you cannot turn off the radio or change the channel. Recall a real-life experience you had when the radio was playing, and you could hear it, but you were not listening to it. The sounds were there, and you could focus on them if you chose to, but they were not of interest to you, so you went about your business while the disc jockey introduced the next unstimulating song. You can notice that these events happen but not let them influence you to dance or sing along. Similarly, you can notice or be mindful of your private events as they happen but not let them influence you to do things that are not values based.

\section{Committed Action: Doing}

Engaging in committed action is a skill executed by psychologically flexible individuals, and can be learned through ACTraining. Committed action is overt behavior in the service of values. Psychological inflexibility is evidenced when an individual is inactive, avoidant, or impulsive. For instance, during the pandemic, a graduate student engages in a psychologically inflexible repertoire (given his values) of ditching the newly established distance-learning classes being taught through teleconferencing. Because the campus is closed, he stays in bed all day, does not answer his texts and e-mails, scrolls through TikTok for hours, puts whiskey in his coffee so he can "catch a buzz," and simply puts an avatar up during class time to deceive the professor into thinking he is present in class. These responses show inactivity, impulsivity, and avoidance, and ACTraining would encourage the development of a list of responses that are more in line with his values, as well as a contingency plan to support an increased rate of these behaviors.

The bottom rows of the MAP set the occasion for "designing success with performance management." Utilizing performance management will support the execution of this new list of committed actions that you will be "doing," and behavior analysts know full well the power of behavioral contracts. The suggestions from this section help to codify how performance management can be applied to the new task list of replacement behaviors. The MAP guides you to use a checklist to provide yourself with antecedent support (e.g., "Make sure all required resources for successful actions have been acquired.") and contingency-management directives ("Publicly announce your commitment to meet performance goals," and "Alert your accountability partner about your commitment and goals."). The inclusion of a place to develop a clear behavioral contract ("Describe incentives, performance criteria, and deadlines.") shows how firmly ACT is attached to traditional behavior analysis and that the domains of ACT (i.e., acceptance, defusion, self-as-context, values, and contacting the present moment) aim to support the performance management approach.

The "doing" component of the MAP comports with committed action in the ACT model and gives instructions to develop an objective to-do list. Behavior analysts are, in general, already very good at setting goals and breaking down tasks to create a to-do list. What might be needed now is improvement in the skill of prioritizing your tasks in line with a radically new context - either you may be overwhelmed with things to do as your work requirements radically shift, or you may be stuck feeling helpless, "doing nothing" at home. For now, genuinely and authentically take a few moments to put pen to paper and develop your to-do list. After you have created the list, select some objectives and write them in your printed-out version of the MAP worksheet. Once completed, look at your to-do list. Does it seem in line with what is most important right now? Hold that thought, and we will return to this list after looking at the next component.

\section{Values: What I Care About}

Authoring, clarifying, and being influenced by one's values is another skill that ACT helps develop by inviting people to explore the significant purpose of their lives and their choices. Values are verbally constructed, freely chosen directions for responses that establish reinforcement for engaging in those personally relevant actions (Wilson \& DuFrene, 2009). When one has not clarified his or her values, he or she is more likely to engage in psychologically inflexible behaviors that are 
influenced by short-term reinforcers or contingencies that are more socially conventional and expected rather than what is personally meaningful. For example, during the pandemic, we, the authors of this article, found ourselves and many of our friends struggling with the same thoughts as the aforementioned preschool director - that with the world and our country in the state it is in, nothing really matters, and there is nothing we can do about it anyway. We, too, found ourselves drinking more, watching quite a few more escapist shows than usual, and dropping projects that had once been important to us. But this article itself reflects our reorientation to what seems most important in this moment - to focus on how we can help, in our own way, even though we are not making masks or engaging in "essential" work during this crisis.

Let us be perfectly clear: Everyone has the right to imbibe their favorite beverage and watch television shows that are entertaining. People can choose the values of "recreation" and "entertainment" to be a part of their repertoire. The same person can also choose "contribution" and "ambition" as values. The context sets the occasion for certain choices to be reinforced. The purpose of values clarification is developing verbal behavior about what is reinforcing to the individual simply by the manner in which the person executes his or her behavior. The ACTraining model suggests that authoring and clarifying one's values can increase psychological flexibility - the ability to change given certain contextual variables - when the environment presents certain difficulties.

The "what I care about" component of the MAP comports with values in the ACT model, gives instructions to develop a list of values, and instructs the person to take the following action: Describe your motivation for engaging in your chosen action and why you aim for optimal performance.

Everything discussed in this article rests on identifying what is important to you, right now, in this moment, as well as what will continue to be important in the future. For most people, times of crisis result in a realignment of priorities and a questioning of what is most important. The shelter-in-place order from the pandemic is like hitting a pause button on the trajectory of life, and so it is a good time for all of us to ask the question "What do I care about?" The pandemic pause button is setting the occasion for everyone to genuinely ponder how we want to be in the world - as individuals unto ourselves and as group members - and reflect on what characteristics will be evident in the quality of our actions.

One solid exercise you can attempt is taking $10 \mathrm{~min}$ and writing out what you want to talk to your loved ones about in the future about how you handled the 2020 pandemic. Truly put pen to paper, and think about a gathering you are potentially attending next year. How do you want to say you behaved during the public health crisis? Imagine attending a major convention in the future and catching up with your close colleagues. What will you be able to say you did, and what were the qualities and characteristics of your actions? This exercise can easily lead to answers that will make us seem like we want to do things that get other people's admiration and social reinforcement, but ponder this exercise a bit more personally and complexly. What do you truly care about deeply, so much so that you will be proud to have acted this way during a challenging time, whether other people reinforce such choices or not? Your values have personal meaning, and simply by acting in the directions governed by these verbal events, such behavior is reinforced. Life is asking us a question: "How do you want to be?" What is your answer?

Now, come back to the to-do list you created in the last section. Recall that we asked: "Does it seem in line with what is most important right now?" Now that you have spent time thinking about what is vital to you, and the characteristics that bring vitality to your behavior, can you see your list as worthy and worthwhile? You might also take the time to make a list of things you have been doing that are not necessarily on your todo list - whether that is "make sourdough," "run on the beach," "have a virtual happy hour with friends," or "bingewatch Netflix and eat popcorn"-and add some of those to your MAP. Can you see how the actions on both these lists align with your values? Are there actions you would like to engage in more effectively? Are there actions on either of these lists that do not seem so important? Now is the time to identify your priorities and commit to them. It may help to use strategies that are well researched in the performance management literature (as discussed previously) and establish a relationship with an accountability partner where you can both develop a contract including incentives, performance criteria, and deadlines for committed actions. And at the same time, we encourage you to be gentle with yourself_- "productivity" is not the goal in times of crisis. Simply doing the next right thing, in the face of adversity, is more than enough.

As you try to engage in values-directed actions, various barriers - distractions and aversive feelings and thoughtswill continue to show up. Notice what is not making it off your to-do list. What have you been doing instead? What might you be avoiding? Come back to the cycle of "I am here now, accepting my feelings and noticing my thoughts while doing what I care about," and see if you can manage some of those barriers a little more easily every time you practice the skills. As you engage in values-directed committed actions while managing distractions, worry, fear, and sadness, you are showing psychological flexibility and achieving the process and outcome of ACTraining.

\section{Conclusion}

The MAP is a flexible tool that can be used in many other environments addressing a myriad of challenges, and it will continue to be useful to you long after this pandemic is over. Because ACT is a transdiagnostic intervention, this checklist 
and related skills can not only be applied to countless human tribulations but also simply improve your ability to live in alignment with your personal and professional values on an ongoing basis. We encourage you to learn more about psychological flexibility as a worthy construct in applied behavioral science, as well as learn more about applying ACT for clients and yourself. The Association for Behavior Analysis International and the Association for Contextual Behavioral Science provide more resources for learning about this powerful intervention. We hope that you continue to use the MAP as an effective guide to engaging in psychological flexibility - not only now in this time of global crisis, but also in the future, as you continue to do good work in the face of all the typical stress and adversity we face as humans in a helping profession.

Funding Not applicable.

\section{Compliance with Ethical Standards}

Conflicts of interest The authors declare they have no conflict of interest.

Ethical approval Not applicable.

\section{References}

A-Tjak, J. G. L., Davis, M. L., Morina, N., Powers, M. B., Smits, J. A. J., \& Emmelkamp, P. M. G. (2015). A meta-analysis of the efficacy of acceptance and commitment therapy for clinically relevant mental and physical health problems. Psychotherapy and Psychosomatics, 84(30), 30-36. https://doi.org/10.1159/000365764.

Bacon, D. L., Fulton, B. J., \& Malott, R. W. (1982). Improving staff performance through the use of task checklists. Journal of Organizational Behavior Management, 4(3-4), 17-25.

Blackledge, J. T. (2007). Disrupting verbal processes: Cognitive defusion in acceptance and commitment therapy and other mindfulness-based psychotherapies. The Psychological Record, 57(4), 555-577. https://doi.org/10.1007/BF03395595.

Boeschen, L. E., Koss, M. P., Figuerdo, A. J., \& Coan, J. A. (2001). Experiential avoidance and post-traumatic stress disorder: A cognitive mediational model of rape recovery. Journal of Aggression, Maltreatment, \& Trauma, 4(2), 211-245. https://doi.org/10.1300/ J146v04n02_10.

Castro, M., Rehfeldt, R. A., \& Root, W. B. (2016). On the role of values clarification and committed actions in enhancing the engagement of direct care workers with clients with severe developmental disorders. Journal of Contextual Behavioral Science, 5(4), 201-207 Retrieved from https://www.sciencedirect.com/science/article/pii/ S2212144716300588.

Doorley, J., Kashdan, T. B., Disabato, D., Goodman, F. R., \& McKnight, P. (2020). Understanding psychological flexibility: A multi-method exploration of pursuing valued goals despite the presence of pain. Retrieved from osf.io/r7v6z (In press).

Gawande, A. (2011). The checklist manifesto. New York, NY: Picador Paper.
Hayes, S. C., Wilson, K. G., Gifford, E. V., Follette, V. M., \& Strosahl, K. (1996). Experimental avoidance and behavioral disorders: A functional dimensional approach to diagnosis and treatment. Journal of Consulting Clinical Psychology, 64(6), 1152-1168 Retrieved from https://www.ncbi.nlm.nih.gov/pubmed/8991302.

Hayes, S. C., Strosahl, K. D., \& Wilson, K. G. (2012). Acceptance and commitment therapy: The process and practice of mindful change (2nd ed.). New York, NY: Guilford Press.

Howell, A., Passmore, H. A., \& Buro, K. (2013). Meaning in nature: Meaning in life as a mediator of the relationship between nature connectedness and well-being. Journal of Happiness Studies, 14, 1681-1696. https://doi.org/10.1007/s10902-012-9403-x.

Howell, A. \& Passmore, H. A. (2019). Acceptance and commitment training (ACT) as a positive psychological intervention: A systematic review and initial meta-analysis regarding ACT's role in wellbeing promotion among university students. Journal of Happiness Studies, 20, 1995-2010.

Kelson, J., Rollin, A., Ridout, B., \& Campbell, A. (2019). Internetdelivered acceptance and commitment therapy for anxiety treatment: Systematic review. Journal of Medical Internet Research, 21(1), e12530. https://doi.org/10.2196/12530.

Killingsworth, M. A., \& Gilbert, D. T. (2010). A wandering mind is an unhappy mind. Science, 330, 932. https://doi.org/10.1126/science. 1192439.

Little, A., Tarbox, J., \& Alzaabi, K. (2020). Using acceptance and commitment training to enhance the effectiveness of behavioral skills training. Journal of Contextual Behavioral Science, 16, 9-16. https://doi.org/10.1016/j.jcbs.2020.02.002.

Moran, D. J. (2011). ACT for leadership: Using acceptance and commitment training to develop crisis-resilient change managers. International Journal of Behavioral Consultation and Therapy, 7(1), 66-75. https://doi.org/10.1037/h0100928.

Moran, D. J. (2013). Building safety commitment. Joliet, IL: Valued Living Books.

Moran, D. J. (2015). Acceptance and commitment training in the workplace. Current Opinion in Psychology, 2, 26-31.

Mueller, P. A., \& Oppenheimer, D. M. (2014). The pen is mightier than the keyboard: Advantages of longhand over laptop note taking. Psychological Science, 25(6), 1159-1168. https://doi.org/10.1177/ 0956797614524581.

Roemer, L., Litz, B. T., Orsillo, S. M., \& Wagner, A. W. (2001). A preliminary investigation of the role of strategic withholding of emotions in PTSD. Journal of Traumatic Stress, 14(1), 149-156. https:// doi.org/10.1023/A:1007895817502.

Törneke, N. (2017). Metaphor in practice: A professional's guide to using the science of language in psychotherapy. Oakland, CA: New Harbinger.

Walser, R., \& Westrup, D. (2007). Acceptance and commitment therapy for the treatment of post-traumatic stress disorder and traumarelated problems: A practitioner's guide to using mindfulness and acceptance strategies. Oakland, CA: New Harbinger.

Westrup, D., \& Wright, J. M. (2017). Learning ACT for group treatment: An acceptance and commitment training manual for therapists. Oakland, CA: New Harbinger.

Wilson, K., \& DuFrene, T. (2009). Mindfulness for two: An acceptance and commitment therapy approach to mindfulness in psychotherapy. Oakland, CA: New Harbinger.

Publisher's Note Springer Nature remains neutral with regard to jurisdictional claims in published maps and institutional affiliations. 